Association for Information Systems AIS Electronic Library (AISeL)

ECIS 2002 Proceedings

European Conference on Information Systems

2002

\title{
Wireless Diffusion and Mobile Computing: Implications for the Digital Divide
}

Jonathan Wareham

Georgia State University, WAREHAM@ACM.ORG

Armando Levy

AnalysisGroup, alevy@analysisgroup.com

Karlene Cousins

Georgia State University, karlenecousins@hotmail.com

Follow this and additional works at: http://aisel.aisnet.org/ecis2002

\section{Recommended Citation}

Wareham, Jonathan; Levy, Armando; and Cousins, Karlene, "Wireless Diffusion and Mobile Computing: Implications for the Digital Divide" (2002). ECIS 2002 Proceedings. 62.

http://aisel.aisnet.org/ecis2002/62

This material is brought to you by the European Conference on Information Systems (ECIS) at AIS Electronic Library (AISeL). It has been accepted for inclusion in ECIS 2002 Proceedings by an authorized administrator of AIS Electronic Library (AISeL). For more information, please contact elibrary@aisnet.org. 


\title{
WIRELESS DIFFUSION AND MOBILE COMPUTING: IMPLICATIONS FOR THE DIGITAL DIVIDE
}

\author{
Jonathan Wareham \\ Department of Computer Information Systems \\ Georgia State University \\ P.O. Box 4015 \\ Atlanta, GA 30302-4015 \\ wareham@acm.org \\ Armando Levy \\ Analysis Group \\ alevy@analysisgroup.com \\ Menlo Park, CA \\ Karlene Cousins \\ Department of Computer Information Systems \\ Georgia State University \\ P.O. Box 4015 \\ Atlanta, GA 30302-4015 \\ karlenecousins@hotmail.com
}

\begin{abstract}
Gaps in the rates of digital inclusion continue to plague certain socio-economic segments of the American economy. For these groups, the migration path towards mobile computing and digital inclusion may transpire from $2 G$ voice centric mobile telephone to the data centric smartphone or wireless PDA. This study investigates what socio-economic factors are determinative to the diffusion of mobile telecommunications; how these findings can be extended to mobile computing; and how these findings can inform managerial and policy making decisions concerning the digital divide.

Using survey data from 1994 and 1998 and a probit model of mobile phone adoption, we estimate the rate of diffusion and bounds for the long run market shares for specific socio-economic market segments in the United States. In contrast to traditional Internet access, neither education nor age are positive predictors of mobile phone adoption. In addition, Afro-Americans have adopted mobile phones at rates significantly higher than the population. These findings have considerable implications for the diffusion of mobile computing devices and the gaps in digital inclusion that may be overcome through the migration of Internet access to alternative devices.
\end{abstract}

\section{THE DIGITAL DIVIDE}

Although lower socio-economic groups are experiencing increasing Internet access, the digital divide continues to command considerable attention from policy makers due to the threat of even greater polarization. US government representatives have set a clear public priority to make Internet connections as common as telephone connections (CNN.com 2000, 2001). Empirical research investigating the digital divide has focused upon a variety of defining social characteristics including 
race, gender, education and age (Hoffman and Novak 1998, 2000; McConnaughey and Lader 2001), but the exact causes are still uncertain.

The good news concerning the digital divide is that the number of individuals who now have a connection to the Internet has increased substantially. The latest report from the US. Commerce Department's National Telecommunications and Information Administration (McConnaughey and Lader 2000) concludes that the share of households with Internet access has grown from $26.2 \%$ in December 1998 to $41.5 \%$ in August 2000, an increase of 58\%. Moreover, the share of individuals using the Internet rose by $35.8 \%$ in the same period. Should this trend continue, the Commerce Department estimates that more than half of all Americans will be using the Internet by the middle of 2001. But while the collective trend is positive in both relative and nominal terms, the policy questions surrounding the digital divide are more concerned with the relative differences between socio-economic groups and how these variances evolve within the aggregate development

The groups traditionally classified as technology "have-nots" have made dramatic gains (McConnaughey and Lader 2000). For example, the disparity in Internet usage between male and female users has diminished. The gap between rural areas and the national average has decreased by 4.0 percentage points, demonstrating a $75 \%$ increase in rural penetration from December 1998 to August 2000. Blacks are now twice as likely to have Internet access then they were 20 months prior, with penetration rates increasing from $11.2 \%$ to $23.5 \%$. Hispanics have made equally impressive gains, growing from $12.6 \%$ to $23.6 \%$.

Despite the fact that Internet access is increasing for almost every group, the digital divide has grown for some groups in the United States. Persons with a disability are only half as likely to have Internet access as those without. Significant gaps also remain within racial groups. For example, Asian-Americans maintain the highest Internet access rates at $56.8 \%$, which overshadows the aforementioned levels of Black and Hispanic households at 23.5\% and 23.6\%, respectively. The gaps between these two groups and the national average are also growing. For Black households, the gap currently is 18 percentage points $(23.5 \%$ for Blacks and $41.5 \%$ national), which has increased 3 percentage points from the previous gap of $15 \%$ in December 1998. For Hispanics, the gap has widened even further. Where the current gap is 17.9 percentage points, it is 4.3 percentage points larger than the 13.6 percentage point gap that existed in December 1998. According to the National Telecommunications and Information Administration, differences in income and education do not fully account for these differences. Estimates of what the Black and Hispanic household access rates would be after correcting for income and education can account for only half the gap (McConnaughey and Lader 2000).

Additional observations on the digital divide show that individuals aged 50 years or older are the least likely to be Internet users. Two-parent households are twice as likely to have Internet access as single-parent households. And rural areas are lagging behind metropolitan regions by 4.9 percentage points ( $7.3 \%$ rural, $12.2 \%$ metropolitan).

Hoffman and Novak (2000) highlight the fact that PC ownership for the Black population is stagnant, while adoption of cable and satellite dish technology is increasing dramatically, suggesting that a possibility exists for Internet adoption through these technologies. Hence, the potential for increasing Internet inclusion rates via alternative technologies among social groups having greater representation within the lower income levels is intuitively obvious. While differences remain between wireless telecom and mobile computing devices, the two technologies are converging into a product segment that offers Internet connectivity at a lower entry cost than the traditional home PC/modem, as well as different behavioral use patterns and technical acumen requirements. These devices offer great potential for increasing Internet inclusion rates for the population groups currently below the national average. 


\subsection{Research Question}

We suggest that the migration path toward mobile computing will proceed from the $2 \mathrm{G}$ voice centric mobile telephone, to the data centric smartphone, and further to $3 \mathrm{G}$ computing devices. Consequently, valuable insights from the diffusion of mobile telecommunications can be garnered to guide managerial and public policy decision-making regarding the growth and dispersion of mobile computing products and their potential impact on the digital divide.

We studied the diffusion patterns of mobile telecommunications based upon pooled crosssection survey samples of households from data gathered by PNR Associates. The first sample, obtained in 1994, contains information from 8,700 households, while the second sample, gathered in 1998, contains over 16,000 households. The data encompass information about demographics, including income, location and constitution of household, profession, gender, race, age and education.

The main research questions are: (1) what socio-economic factors are determinative to the diffusion of mobile telecommunications; (2) how can these findings be extended to mobile computing; and (3) how can these findings inform managerial and policy decisions concerning the digital divide? In order to address these issues, the paper is organized as follows.

Section 2 surveys predominant practice in the econometric methods applied to estimate diffusion patterns and delineates the techniques that are employed in our study. In Section 3, we develop the diffusion models based on socioeconomic factors. Prospects for the diffusion of mobile computing are explored in Section 4. Finally, we extend the implications drawn from the analysis to the concerns of managerial and policy decision making, mobile computing and the digital divide.

\section{DIFFUSSION MODELS}

The diffusion of technology and products has been approached by a number of different perspectives including sociology (Rogers 1995), economics (Gurbaxani 1990), geography (Brown 1981, Clarck 1984) and marketing and consumer behavior (Mahajan, Muller and Bass 1990). The most widespread way of estimating models of diffusion on pooled cross-section or aggregate time-series data is to use a two-stage procedure that was first introduced by Grilliches (1957) in his seminal study on hybrid corn. In the first stage, a logistic, or some other S-shaped curve, is imposed on the data on a proportion of the adopters. The second stage consists of using a linear regression to explain the slope coefficient of the fitted curves representing diffusion speed in terms of various exogenous or endogenous factors (Mansfield 1961, Artle and Averous 1973).

Our study builds upon this technique by estimating diffusion rates and upper bounds on the penetration levels across the population based upon geographic area and income levels, similar to a one-stage aggregate diffusion model (Rholfs 1973). Although the significance found on both income and size of metropolitan area is illuminating, we drop the assumption that the diffusion process is the same across markets and focus on socio-economic heterogeneity (Chatterjee and Eliashberg 1990). Socio-economic factors that explain statistical variation in adoption rates for cellular phones are used to identify groups with different diffusion rates as well as long-term market shares. The analysis concludes by identifying two groups from the population with distinctive diffusion speeds and saturation levels.

\section{SURVEY DATA AND ANALYSIS}

The data used in this study consists of two cross-sectional survey samples of households conducted by PNR Associates. The first sample obtained in 1994, contains information from 8,700 households. The second sample gathered in 1998, contains over 16,000 households. Each household completed a questionnaire and submitted copies of its telephone bills. The questionnaire asked whether a household member owned a mobile telephone as well as questions related to the 
composition of the household, education of the head of household, income, and other socio-economic factors.

In Table 1, we list the proportion of households that owned a mobile telephone in 1994. Since two main determinants of mobile adoption are the wealth of the respondent and the potential size of their wireless network, we segmented the data by annual household income and the size of the

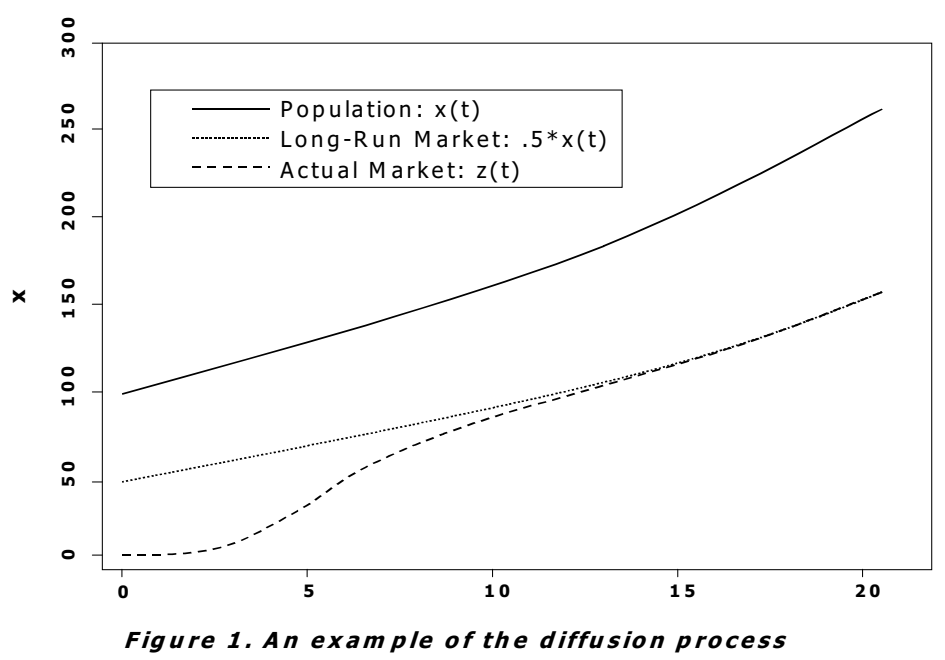
metropolitan service area used by the census excluding cells in the table if there were less than thirty households in a category.

Table 2 gives the upper bounds on market size implied by the penetration rates in 1994 that were given in Table 1 as determined by long term population growth. The long-run market shares are largest among households with high levels of income, and at slightly higher rates in larger metropolitan areas. However this assumption that the diffusion process is the same across markets may not fit well when market segments have different attitudes towards experimentation with new products. This "bounding" approach will be more appropriate when markets are geographically distinct but similar in socioeconomic terms.

Another description of the diffusion process would allow different processes across markets. For example, the young "technology-literate" may have a higher rate of adoption than retirees over 65 years of age. We also expect the rate of adoption to be positively related to the long-run market share. In this case, when the diffusion is positively related to the long-run market share, a higher penetration rate for one market over another at any point in time will persist, but over time we expect large variations in adoption rates to emerge early in the diffusion and to lessen later. Socio-economic factors which explain statistical variation in the adoption rates for cellular phones identify groups with different diffusion rates and long-run market shares. In the next section, we specify a class of diffusion processes which vary with the long-run market share.

\subsection{A Diffusion Model of Market Heterogeneity}

Firstly, we need to identify those socio-economic factors which differentiate market segments for cellular phones. Table 3 displays maximum likelihood estimates for a probit model of cellular adoption. Estimates are shown from the 1994 sample, the 1998 sample and the combined sample.

Table 3 shows that the most important predictor of cell phone adoption is income, which is significant across all three models. The size of the household's metropolitan service area, marital status and occupation of the head of household are also positive predictors of cell phone demand. People in sales positions consistently adopt cell phones at the highest rates, followed by executives, while professionals do not adopt at significantly higher rates than the general population. Given the travel inherent in sales and executive positions, this confirms our intuition. Black respondents adopted cell phones at higher rates than the general population, while Hispanic and Asian respondents are not statistically different from the general population. The presence of children was found to be a consistent negative predictor of cell phone adoption. Since households with children are generally less mobile than those without, this is expected. 
Neither education nor age seem to be significant predictors of mobile phone adoption.

\subsection{Market Heterogeneity and Long-Run Market Share}

In capturing the dependence of the diffusion process $y_{t}$. on the long-run market share, we specify our diffusion as:

$$
y_{t}(\alpha)=\int_{0}^{\alpha \theta t} f(u) d u=F(\alpha \theta t)
$$

where $\theta$ is a parameter to be estimated. This specification allows us to re-scale the time dimension of a baseline diffusion $f$ according to $\theta$ and $\alpha$. Hence, $f$ is the diffusion process when the long-run market share is 1 , and for any $\alpha<1$, the rate of diffusion will be proportionally slower. For example, if $\alpha=.5$, then at time t $y_{t}(.5)=F(\theta t / 2)$, while if $\alpha=.25$ then $y_{t}(.25)=F(\theta t / 4)$. The parameter $\theta$ serves to scale the baseline diffusion to the data.

When we have measures of the adoption rates at two points in time for a market segment, we can estimate both $\alpha$ and $\theta$. If we observe penetration rates at two time periods:

$$
\begin{aligned}
& s_{i t}=\frac{x_{i t}}{z_{i t}} \text { and } s_{i, t+k}=\frac{x_{i, t+k}}{z_{i, t+k}} \text { then : } \\
& s_{i t}=\alpha_{i} F\left(\alpha_{i} \theta t\right) \text { and } s_{i, t+k}=\alpha_{i} F\left(\alpha_{i} \theta[t+k]\right)
\end{aligned}
$$

which gives two nonlinear equations in two unknowns. Solving the system will give us estimates of $\alpha$ and $\theta$. However, if two or more market segments are available, then we can identify each parameter $\alpha$ for each market and $\theta$.

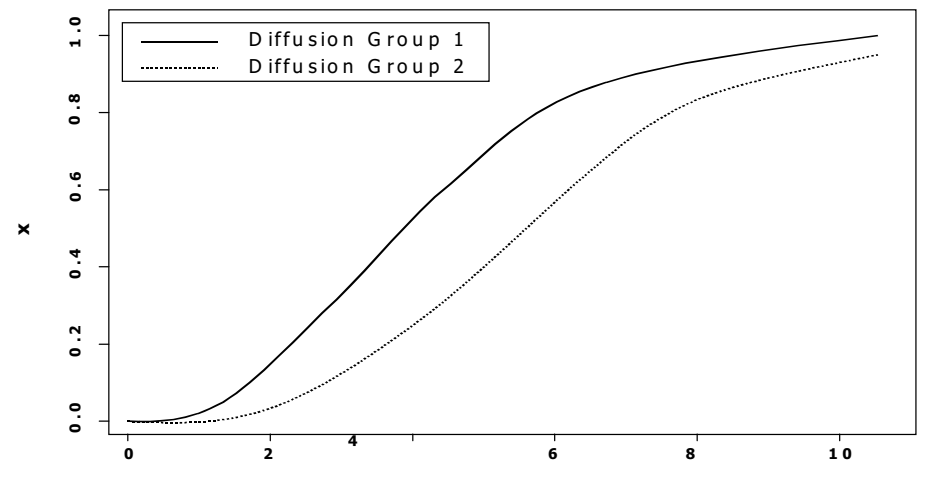

Figure 2. Estimated diffusion processes forgroups 1 and 2 from 1990
Using our results

from Table 3, we estimated diffusion curves for two different population groups which had disparate adoption rates. In group 1, the fast adopters, we include all households where the occupation of head of household was either in sales or an executive

position, the incomes are over $\$ 40,000$ per year and no children are present. All other households fall into group 2, which we categorize as the general population. In 1994, 18.6\% of group 1 households owned a cellular phone, while only $6.4 \%$ of group 2 households owned a cellular phone. In 1998 these figures had grown to $31.3 \%$ and $20.7 \%$, respectively. Using these figures, we solved for $\alpha_{1}, \alpha_{2}$ and $\theta$ by solving the system of four equations given by (2) for groups 1 and $2 .{ }^{1}$ The solutions are given by $(.324, .237,3.19)$, hence we predict a long-run market share of $32.4 \%$ for group 1 and $23.7 \%$ for group 2. Figure 2 shows the diffusion processes for groups 1 and 2 measured in years since 1990 . We see from the figure that in 1994 about $60 \%$ of households in group 1 that would adopt in the long run have done so, whereas only about $30 \%$ of the households in group 2 had adopted cellular technology.

\footnotetext{
${ }^{1}$ We did this by a modified Newton-Raphson algorithm.
} 
However by 1998 , more than $90 \%$ of the long-run market in group 1 had adopted, as had over $85 \%$ of the group 2 market.

\section{IMPLICATIONS}

Given that the results are based on $2 \mathrm{G}$ mobile telecom data, the question arises as to how these results can be extrapolated to the diffusion of data-centric computing devices. The greatest barrier to such an extrapolation is the heterogeneity embodied in mobile computing that is currently not present in traditional mobile telephones. While a greater increase in breadth of function will be enabled by the larger bandwidth employed in $3 \mathrm{G}$ applications, the coming generation of devices deployed in $2 \mathrm{G}$ or $2.5 \mathrm{G}$ networks will remain constrained by bandwidth limitations, and, as a consequence, be limited in functional heterogeneity. We can, therefore, cautiously employ the findings of mobile diffusion to inform the adoption of currently available mobile computing devices

\subsection{Implications for Mobile Computing}

Intuitively, the positive correlation between income levels and mobile telephone adoption should be able to be extended to mobile computing applications. While the size of the metropolitan area of the household is also a positive indicator, this factor is more ambiguous. There is a weak implication that the positive correlation results from positive network externalities, that is, the value of the mobile telephone is correlated with the size of the network. Whether these factors are equally relevant in the relationship between city size and mobile computing devices is difficult to postulate, but we believe that it would have less significance with increasingly heterogeneous mobile computing applications.

The occupation of the head of household is a strong predictor of mobile phone adoption. We expect this correlation to be equally strong in mobile computing applications because we assume that a great deal of the functionality offered in these devices will complement and support diverse professional occupations as well as vertical applications. For example, doctors may be prone to use one type of device, while sales personnel and executives who are more mobile may adopt another. As applications become increasingly heterogeneous, occupation should be a positive predictor of both adoption rate and type of application.

Other positive predictors of cell phone demand are more opaque. Black respondents adopted cell phones at higher rates than the general population, while Hispanic and Asian respondents are not statistically different. This result is difficult to understand in the context of mobile telecommunications and equally problematic to extrapolate to mobile computing applications. The presence of children was found to be a consistent negative predictor of cell phone adoption. Conversely, being married is a positive predictor of mobile phone adoption. Neither education nor age seem to be significant predictors of mobile phone adoption.

As mobile computing applications emerge, it will be interesting to determine if, and why, differences emerge within ethnic groups. It is assumed that education levels equate with greater technical literacy and higher adoption rates. This certainly has not proven correct in our sample, but differences may emerge if applications become more technically demanding. However, as most products within multimedia and telecommunications evolve, user friendliness has been stressed in an effort to broaden the market to the general population. If this is the case with applications, then education may continue to be insignificant. A similar argument can be made concerning age. Should applications require technical proficiency, we may find some negative correlation with age and adoption levels. Should applications be designed to serve the needs of a general market, then age will not be a significant predictor.

In identifying two major groups in the population as either fast adopters - group 1, and normal representatives of the population - group 2, we can make certain predictions about mobile computing 
applications. For fast adopters, their adoption rates will likely be faster than the rest of the population. Marketing expenditures targeted at these groups normally considered rich target markets may, in fact, be delinquent and sub-optimally applied. For example, as early as 1994 , about $60 \%$ of households in group 1 who would adopt in the long run had already done so, whereas only about $30 \%$ of the households in group 2 had adopted mobile communications! While speculative, few would claim that it was common belief that $60 \%$ of the market for sales professionals would be penetrated as early as 1994. As early as 1996, group 1 was approaching full saturation levels at $85 \%$, whereas group 2 remained at roughly $55 \%$, a difference of $30 \%$. By 1998 , group 1 had attained $90 \%$ saturation, whereas group 2 had attained $85 \%$. So, not only are diffusion rates significantly faster in the intuitively appealing target markets, long-term saturation rates may arrive earlier than otherwise anticipated (see Figure 2).

\subsection{Implications for the Digital Divide}

This analysis has several interesting implications for the digital divide. While education is a predictor of mobile phone adoption, it is neither statistically nor economically significant. Thus the adoption of mobile computing devices may be less likely in higher educational levels than has previously been reported in the statistics concerning traditional Internet inclusion (Hoffman and Novak 1998, 2000). Telephone devices require less technological proficiency than personal computers to operate, so Internet access through smartphones may eliminate some of the adoption barriers typically associated with lack of education.

Income levels should continue to be both economically and statistically significant predictors of mobile computing adoption. However, as Internet access becomes available on the lower price points offered by simple devices such as smartphones, the acquisition costs of these devices should include total cost of ownership measures, where subscription fees may become equally determinative to adoption behavior.

Where age was a negative and significant predictor of mobile phone adoption in the 1994 sample, the effect dissipated in the 1998 and pooled sample. It will be interesting to follow whether mobile computing devices are more frequently adopted by users above the age of 50 years, as this age group has historically been the least likely to adopt traditional PC-based Internet access.

The presence of children in the household has consistently been a negative predictor of mobile telecom adoption, and we can expect this to hold with mobile computing devices in the near term. However, as the total cost of ownership of both mobile telecom and computing devices falls, we may see a greater frequency of adoption within specific applications. For example, in Europe SMS messaging has become extremely popular amongst younger age groups (Secker 2001), and iMode is enjoying great popularity with the younger generations in Japan (Dodgsen 2001).

Executives and sales professionals have consistently adopted mobile telephones at higher rates than the population. This trend should continue for mobile telecom applications. However, the highest adoption rates of mobile computing applications have been in vertical applications within specific industry sectors (Anderson 2000, Weber 2000). This trend is expected to continue but we cannot expect these applications to have significant effects on the digital divide in the immediate future as these devices will most likely be employed by social groups with higher rates of inclusion. Future research should focus on the characteristics of industry sectors that make the adoption of vertical applications attractive and how this may influence groups with low inclusion rates.

We have little theoretical intuition as to why Black respondents adopt mobile telephones at rates significantly higher than the population. The adoption of cable and satellite dish technology is also increasing dramatically in the Black population. (Hoffman and Novak, 2000). While we may need to turn to marketing, consumer behavior or economic anthropology to answer why this may be the case, the migration path from mobile telephones to browser-enabled smartphones could be feasible for this specific social group. We are reminded of the fact that social heterogeneity accounts for some 
of the variance in consumption choices that can not be simply eliminated by statistical controls and that educational and income differences only account for half the Internet inclusion gap between Blacks and the general populace (McConnaughey and Lader 2000). Hence, our analysis supports the argument that, for some groups, the path to digital inclusion may be through alternative means such as smartphones, web-enabled television, or other multimedia devices.

Our analysis demonstrated how specific groups of the population adopted mobile telephones significantly faster than the population. For example, for our group of fast adopters of mobile telecom, the market reached penetration rates as high as $60 \%$ as early as 1994 , compared to $30 \%$ for the rest of the population at the same time. Thus for social groups that have a demonstrated propensity to adopt other forms of technology at significantly higher rates than the general population, Internet inclusion can be most effectively increased by migrating the Internet to the device rather than other policy measures aimed at changing behavior and consumption decisions.

\subsection{Limitations}

While adoption of mobile telephones is fairly simple, and can be captured in a binary response model as an all-or-nothing decision without oversimplification, mobile computing devices will be both more sophisticated and heterogeneous. Modeling adoption as a static decision may neglect important information about level and type of use. In addition, the assumption that mobile computing is a logical descendant of mobile communications may not hold as the breadth of functionality expands. Finally, this study has neglected the manner in which mobile communications technology has improved through time. As technology improves in terms of efficiency, applicability and relative economy, it should be possible to identify different development stages, or generations, presenting distinct diffusion courses (Baptista 1999). The improvement of technology is an important parameter that can determine its diffusion path, and that has been neglected in this study. For computing devices still in conception, the relative evolution in the functionality/yield relationships should significantly affect diffusion patterns.

\section{CONCLUSION}

This study has examined the diffusion of mobile telecommunications based on cross-pooled samples of data from 1994 and 1998. As expected, we have found that mobile telephone adoption is positively correlated with income, metropolitan area and occupation, specifically sales and executive professionals. However, other parameters of our estimated model were curious. For example, we found that one ethnic group, African Americans, adopted mobile phones significantly faster than the general population, whereas families with children were clearly negatively correlated. Neither age nor education levels were correlated with mobile phone adoption. Given these socio-economic parameters, we have identified two distinctive groups of the population: fast adopters and the general population.

We extrapolated these findings to predict the adoption of mobile computing devices. We expect that occupation will continue to be an important predictor of mobile computing devices, as the functionality offered will support specific professions. Neither age nor education will be determinative for mobile computing devices, assuming that the interface design of these devices is targeted toward the general population and does not require above-average technical proficiency. Finally, there will be specific groups in the population that adopt computing devices significantly faster than the general population. Penetration levels in these groups will be higher than for the population at large. This can have implications for development and marketing of mobile computing products.

These insights can be applied to predict how mobile telecom diffusion may affect the digital divide as Internet access is embraced by smartphones and wireless PDAs that run on $2 \mathrm{G}$ and $2.5 \mathrm{G}$ networks. Education and age are not positive predictors of mobile telephone adoption, as they are with traditional Internet inclusion. Thus the slow adoption rates correlated with low education levels or 
high age may not negatively affect Internet adoption when offered on a mobile computing device. Moreover, Afro-Americans, with traditionally low inclusion rates on traditional PCs, may in fact have greater rates of inclusion when mobile computing devices become commercially available at certain price levels. These findings have significant implications for both marketing and policy decisions in that the introduction of alternate devices and media may be particularly effective in increasing Internet inclusion rates in social groups currently below national averages.

\section{REFERENCES}

Anderson, K. R. (2000) “Wireless Web: Still More Hype than Reality,” Informationweek, 811, October 6, pp. 206-7.

Artle, R. and Averous C. (1973) "The telephone system as a public good: static and dynamic aspects," Bell Journal of Economics and Management Science, vol. 4, pp. 89-100.

Baptista, R. (1999) “The Diffusion of Innovations: A Selective Review," International Journal of the Economics of Business, 6, 1, Feb., pp. 107-129.

Brown, L.A. (1981) Innovation Diffusion: A New Perspective. London: Methuen.

Chatterjee, R. and Eliashberg, J. (1990) "The Invasion Diffusion Process in a Heterogeneous Population: a Micro-modeling Approach," Management Science, 36, pp. 1057-79.

Clarck, G. (1984) Innovation Diffusion: Contemporary Geographical Approaches. Norhich: Geo Books.

CNN.com (2000) "Clinton pushes to help disabled bridge 'digital divide'," September 21, http://www.cnn.com/2000/ALLPOLITICS/stories/09/21/clinton.digital/index.html

CNN.com (2001) “ Clinton calls for more government spending on IT," February 20, http://www.cnn.com/2001/TECH/industry/02/20/clinton.at.oracle.idg/index.html

Dodgson C. (2001) "Who needs iMode?" Communications International, London, Jan., p.37.

Grilliches, Z. (1957) "Hybrid Corn: An Exploration in the Economics of Technological Change," Econometrica, 48, pp. 501-22.

Gurbaxani, V. (1990) "Diffusion in Computing Networks: The Case of BITNET," Communications of the ACM, 33,12 , pp. 65-75.

Hoffman, D.L. and Novak, T.P. (1998) "Bridging the Racial Divide on the Internet," Science, 280, April 17, pp. 390-391.

Hoffman, D.L. and Novak, T.P. (2000) "The Growing Digital Divide: Implications for an Open Research Agenda," in Brynjolfsson, E. and B. Kahin eds. Understanding the Digital Economy. Cambridge, MA: MIT Press.

Mahajan, V., Muller E. and Bass, F.M. (1990) "New Product Diffusion Models in Marketing: A Review and Directions for Research," Journal of Marketing, 54, pp. 1-26.

Mansfield, E. (1961) “Technical Change and the Rate of Imitation,” Econometrica, 29, pp. 741-66.

Mansfield, E. (1968) Industrial Research and Technical Innovation. New York: Norton.

McConnaughey, J. and Lader, W. (2000) "Falling Through the Net II: New Data in the Digital Divide." National Telecommunications and Information Administration, Office of Policy Analysis and Development, United States Department of Commerce.

http://www.ntia.doc.gov/ntiahome/digitaldivide/execsumfttn00.html

Rogers, E.M. (1995) Diffusion of Innovations. New York: The Free Press.

Rohlfs, J. (1973) "A theory of interdependent demand for a communications service," Bell Journal of Economics and Management Science, vol. 4, pp. 16-37.

Secker, M. (2001) "SMS still in strong growth mode," Telecommunications, 5 (5) May, Dedham, p. 12.

Weber, T. (2000) "Waiting for the M-plosion," Telephony, 239(17), October 23, pp. 36-46. 
Table 1: Penetration Rates for Mobile Telephones 1994

\begin{tabular}{|c|c|c|c|c|c|c|}
\hline \multirow[t]{2}{*}{ Incom e } & \multicolumn{6}{|c|}{ Size ofM etropolitan Service A rea* } \\
\hline & N on $-\mathrm{M}$ SA & $50-250$ & $250-500$ & $500-999$ & $1000-2500$ & $2500+$ \\
\hline under $\$ 7500$ & 0 & $0 * \star$ & $0 * \star$ & $0 * \star$ & $.001 \star \star$ & .002 \\
\hline$\$ 7500-\$ 9999$ & $0 * \star$ & $0 * \star$ & - & 0 & .017 & .024 \\
\hline$\$ 10000-\$ 12499$ & .012 & .024 *夫 & $0 * \star$ & $0 \star \star$ & $.048 * \star$ & $.071 * \star$ \\
\hline$\$ 12500-\$ 15000$ & .009 & $.053 * \star$ & $0 * \star$ & $.051 * \star$ & $.068 * \star$ & $.073 \star \star$ \\
\hline$\$ 15000-\$ 19999$ & .005 & $.040 \star \star$ & $.049 * *$ & $.030 * \star$ & .037 & $.044 * \star$ \\
\hline$\$ 20000-\$ 24999$ & .034 & .016 & .039 & 0 & .052 & .048 \\
\hline$\$ 25000-\$ 29999$ & .021 & $.038 * \star$ & $0 * *$ & $.059 * \star$ & .031 & .021 ** \\
\hline$\$ 30000-\$ 34999$ & .046 & .010 & $104 \star \star$ & $100 * \star$ & .040 & .055 \\
\hline$\$ 40000-\$ 44999$ & .085 & $101 \star \star$ & $.089 \star \star$ & $139 * \star$ & .070 & .051 \\
\hline$\$ 45000-\$ 49999$ & .035 & $.036 * \star$ & $.064 * \star$ & $.061 * \star$ & .060 & .060 \\
\hline$\$ 50000-\$ 59999$ & $.083 * \star$ & $.083 * \star$ & $.123 * *$ & $140 * *$ & .086 & 141 \\
\hline$\$ 60000-\$ 69999$ & 104 & $.095 * \star$ & $.151 * \star$ & .157 & 137 & .135 \\
\hline$\$ 70000-\$ 69999$ & $149 * *$ & $143 * \star$ & $101 * *$ & $163 * \star$ & 158 & 167 \\
\hline$\$ 70000-\$ 74999$ & - & - & - & - & $179 * \star$ & 189 \\
\hline$\$ 75000-\$ 99999$ & - & - & $.148 * \star$ & $222 \star \star$ & 266 & 214 \\
\hline \$100000-\$149999 & - & - & - & - & $353 * \star$ & $318 * \star$ \\
\hline \$150000-\$199999 & - & - & - & - & $.467 \star \star$ & $357 * \star$ \\
\hline \multicolumn{7}{|l|}{ * in thou sands } \\
\hline
\end{tabular}


Table 2: Upper Bounds for Long-Run Market Share

\begin{tabular}{|c|c|c|c|c|c|c|}
\hline Incom & & & Size of 1 & ropolitan & Service & \\
\hline e & Non-MS & & $-25^{\text {Area }_{5}^{*}-50}$ & -99 & -250 & \\
\hline under & $\overline{\mathrm{A}}$ & 0 & 0 & 0 & & $\begin{array}{l}2500+ \\
.00\end{array}$ \\
\hline$\$ 7580-\$ 999$ & & 0 & 0 & 0 & & .05 \\
\hline$\$ 1000-\$ 1249$ & & & 0 & 0 & & .15 \\
\hline$\$ 1250-\$ 1500$ & & & 0 & & & .15 \\
\hline$\$ 1500-\$ 1999$ & & & & & & .09 \\
\hline$\$ 2000-\$ 499$ & & & & 0 & & .10 \\
\hline$\$ 2500-\$ 2999$ & & & 0 & & & .04 \\
\hline$\$ 3000-\$ 3499$ & & & & & & .11 \\
\hline$\$ 4000-\$ 4499$ & & & & & & .10 \\
\hline$\$ 4500-\$ 4999$ & & & & & & .12 \\
\hline$\$ 5000-\$ 5999$ & & & & & & .30 \\
\hline$\$ 6000-\$ 6999$ & & & & & & .28 \\
\hline$\$ 7000-\$ 6999$ & & & & & & .35 \\
\hline$\$ 7000-\$ 7499$ & - & - & - & - & & .40 \\
\hline$\$ 7500-\$ 9999$ & - & - & & & & .45 \\
\hline$\$ 10000-\$ 14999$ & - & - & - & - & & .68 \\
\hline$\$ 15000-\$ 19999$ & - & - & - & - & 1 & .76 \\
\hline
\end{tabular}

* in thousands 
Table 3: Probit Maximum Likelihood Estimates

\begin{tabular}{|c|c|c|c|}
\hline \multirow{2}{*}{\begin{tabular}{|l} 
\\
V ariable
\end{tabular}} & $\begin{array}{c}1994 \\
\text { Sam ple }\end{array}$ & 1998 & \multirow[t]{2}{*}{ Pooled Sam ple } \\
\hline & & Param eter Estin & \\
\hline \multirow{2}{*}{ constant } & $-2.4894 *$ & $-1.6699 *$ & $-22155^{\star}$ \\
\hline & $(0.1248)$ & (0 1713) & $(0.0555)$ \\
\hline \multirow[t]{2}{*}{ incom e } & $0.1103 *$ & $0.0718 *$ & $0.0777 *$ \\
\hline & $(0.0072)$ & $(0.0028)$ & $(0.0025)$ \\
\hline \multirow[t]{2}{*}{ edu } & 0.013 & $-2.60 \mathrm{E}-04$ & 0.0085 \\
\hline & $(0.0237)$ & $(0.0106)$ & $(0.0095)$ \\
\hline \multirow[t]{2}{*}{ age } & $-0.0355^{*}$ & 0.0021 & 0.001 \\
\hline & $(0.0107)$ & $(0.0039)$ & $(0.0037)$ \\
\hline \multirow[t]{2}{*}{ pop } & $0.0404 *$ & 0.0098 & $0.0148 *$ \\
\hline & $(0.0125)$ & $(0.0053)$ & $(0.0049)$ \\
\hline \multirow[t]{2}{*}{ hhsize } & $-0.0565 *$ & $0.0408 *$ & $-0.027 *$ \\
\hline & $(0.0243)$ & $(0.0149)$ & $(0.0094)$ \\
\hline \multirow[t]{2}{*}{ ow n } & -0 1667* & $0.1332 *$ & 0.0222 \\
\hline & $(0.0610)$ & $(0.0329)$ & $(0.0267)$ \\
\hline \multirow[t]{2}{*}{ m arried } & 0.1199 & $0.0615 *$ & $0.0916 *$ \\
\hline & $(0.0625)$ & $(0.0307)$ & $(0.0271)$ \\
\hline \multirow[t]{2}{*}{ child } & -0.0386 & $-0.1331 *$ & $-0.0655^{\star}$ \\
\hline & $(0.0641)$ & $(0.0376)$ & $(0.0226)$ \\
\hline \multirow[t]{2}{*}{ exec } & $0.4190 *$ & $0.1138 *$ & $02067 *$ \\
\hline & $(0.0579)$ & $(0.0348)$ & $(0.0293)$ \\
\hline \multirow[t]{2}{*}{ prof } & 0.0081 & 0.0301 & 0.0061 \\
\hline & $(0.0648)$ & $(0.0396)$ & $(0.0329)$ \\
\hline \multirow[t]{2}{*}{ sales } & $0.5498 *$ & $0.1808 *$ & $02813 *$ \\
\hline & $(0.0789)$ & $(0.0505)$ & $(0.0421)$ \\
\hline \multirow[t]{2}{*}{ student } & $0.4144 *$ & & \\
\hline & (0 1867) & & \\
\hline \multirow[t]{2}{*}{ hisp } & 0.0109 & 0.0138 & 0.0193 \\
\hline & $(0.0978)$ & $(0.0344)$ & $(0.0323)$ \\
\hline \multirow[t]{2}{*}{ black } & $02924 *$ & $0.1324 *$ & $01576 *$ \\
\hline & $(0.1144)$ & $(0.0660)$ & $(0.0568)$ \\
\hline \multirow[t]{2}{*}{ asian } & 02195 & -0.0409 & 0.0936 \\
\hline & (0.1753) & (0 1732) & $(0.1227)$ \\
\hline \multirow[t]{2}{*}{ dum m y (1998) } & & & 0.3059 \\
\hline & & & $(0.1305)$ \\
\hline n & 8,731 & 16,089 & 24,820 \\
\hline log likelihood: & $-2,195$ & $-7,792$ & $-10,063$ \\
\hline \multicolumn{4}{|c|}{ standard errors in parenthesis\} } \\
\hline * significantatt & & & \\
\hline
\end{tabular}

